\title{
The Structural Approach and Default Risk
}

\author{
Arsalan Azamighaimasi \\ School of Management, Wuhan University of Technology \\ 205 Luoshi Road, Wuhan 430070, Hubei, China \\ Tel: 86-134-7607-5493 E-mail: Arsalan.azami2011@gmail.com
}

Received: July 18, 2012

Accepted: December 10, 2012

Online Published: December 23, 2012

doi:10.5430/ijfr.v4n1p66

URL: http://dx.doi.org/10.5430/ijfr.v4n1p66

\begin{abstract}
This paper studied and developed credit risk models. Specifically, it focuses on the Merton model, its extensions model, and the way to survey new structural approach. Firstly, this paper has described the Merton model. And then, it has reviewed the first-passage model with more focus on default point. Finally, we considered the new structural approach which stressed that if the firm's value passes the threshold level $b$, the firm's value will continues unless the value process crosses and spends an exogenous quantity of time $b^{-}$below. We have used the Yildiray Yildirim model and ruin probability.
\end{abstract}

Keywords: Merton models, Threshold level, New structural approach, Ruin probability

\section{Introduction}

Credit risk refers to the risk because of unpredictable changes of credit of counterparty risk. The credit worth of a borrower influence on decision; the firm's cost of capital, the credit spreads, and the prices of credit and hedge ratios of credit derivatives, since it is uncertain whether the firm will be able to fulfill its obligation.

The past few years have developed the credit risk modeling which becomes a key component in the risk management systems at financial institutions. Mostly the financial institutions have a tremendous challenge to expectation of default. More precisely firms want to clarify the timing of default and knowing that if a firm's value reached the barrier level, will the firms facing with default in offing?

There are two basic types of the credit risk literature: structural and reduced form models. Merton's models (1974) considered of asset and debt values. He mentioned that if default occurred, the values of assets or shares crosses from the barrier line of outstanding debt.

First passage model introduced by black \& cox (1976). They extended the Merton's model, which mentioned that, the firm may default at any time, not only at the maturity date. If the value of firm dropped below the barrier level at any point before the maturity date, the firm considered to have violated one of the safety covenants' and the firm immediately goes into default.

The severity of ruin introduced by Gerber, Goovaerts and Kass (1987) in the classical risk model, where the risk process is a compound Poisson process, and the premium rate is constant.

Dufresne and Gerber (1988) in the classical risk model, where the risk process is a compound Poisson process, and the premium rate is constant. They make an explicit formula for the severity of ruin if the claim amount distribution is a translation of a combination of exponential distributions

Dickson \&Waters (1992) showed that calculate the probability and severity of ruin in both finite and infinite time and explained that how the algorithms can be implement to provide approximate values for the same amounts in the classical continuous time risk model.

Leland (1994) and Leland \& Toft (LT, 1996) develop structural models that include Debt has average maturity T $<\infty$, Coupon interest is taxing deductible, Default incurs default costs.

The Longstaff and Schwartz (1995) presented that the time varying interest rates in that it allows for a stochastic that is among other thing means that the yield curve is not flat and generalizing the form of the default barrier to account for the debt level (Briys and de Varenne, 1997; Hsu et al., 2002; Hui et al., 2003). 
Yildiray Yildirim (2006) extended block \& cox models as new structural models. He mentioned there is a problem of triggering the default process. Whenever the process is below the barrier, the value process could be below the barrier but close to the barrier level for the moment. In this situation, the firm will still survive.

This paper concerned about bond issued by governments and firms which is every moment faced with the credit risk. The first part, we explained the Merton model briefly. The second part, we considered the first passage model and default time. The third part, we expressed the new structural approach along with analyzed the new structural approach and finally we focus on the ruin probability and how do we get the probability and severity of ruin. If the severity of ruin is not high it means that the price of fluctuation is remarkably close to the threshold level.

\section{Merton Model}

Merton's models (1974) presumed that the value of the firm, V, through time can be described by a diffusion-type stochastic process with stochastic differential equation (SDE). We want to compute pricing of bonds issued by a firm and the firm's asset as follows by

$$
\mathrm{dV}=\mu \mathrm{Vdt}+\sigma \mathrm{Vt} d \mathrm{dt}
$$

This equation defines the Brownian motion. To derive an equation for the value $f(V, t)$ of an option, we may start from equation first. Where $\mathrm{V}$ is the total value of the firm, $\mu$ is the expected continually compounded return on $\mathrm{V}$ or drift (i.e., the asset drift), $\sigma$ is the volatility of firm value and $\mathrm{dW}$ is a standard Weiner process $=\varepsilon d_{t}^{\frac{1}{2}}$ or $\varepsilon \sqrt{d t}$ (where $\varepsilon$ is the standard normal distribution).

When we buy a bond we actually buy a cash flow then there is a dividend like income stream $\boldsymbol{\delta}$ for the holder of the asset. This dividend yields related to the cash flows generated by the assets in place, the equilibrium equation for the total expected return $\boldsymbol{\mu}$ written by

$$
\mu=\alpha+\delta
$$

And then:

$$
\mathrm{dV}=(\mu-\delta) \mathrm{Vdt}+\sigma \mathrm{V} \varepsilon \sqrt{\mathrm{dt}}
$$

According to Merton model default time $\tau$ is a discrete variable,

$$
\tau=\left\{\begin{array}{lll}
T & \text { if } & V_{t}<b \\
\infty & \text { if } \quad \text { else }
\end{array}\right.
$$

The firm default occurs if the value of firm's assets is less than the promised debt repayment at time T. It means that if the event of default occurs when the firm value reaches and crosses the default barrier which is the face value of the debt. Under Merton's model, default cannot take place before the maturity of the debt. If default occurred before maturity of date under Merton's model assumption the default do not take place, whereas we will see a later that, under first passage model, the default can take place before the end of period.

However, under both of those models assumptions, if the firm is getting into financial difficulty and the price of share or the firm's value crosses the default barrier, the firm would not be survive anymore. In this paper wants follows the Yildiray Yildirim model who has considered that if the firm's value crosses the default barrier at first time it can be surviving under specific conditions. He proposed a new extension to the structural model. The default is that take place the first time that the cumulative area of the process below a threshold barrier exceeds an exogenous level.

\section{First Passage Models}

These models introduced by Black and Cox (1976) as extending of the Merton models .it says that the firm facing with default before the maturity date, not only at the end of contract. According to this model a time dependent to default threshold and assume that the default threshold is a constant $(K>0)$. If we have normal condition, no default, and $V_{t}>K$ it means that value of the firm at time $t$ is greater than of default threshold, then the time of default $\tau$ given by

$$
\tau=\inf \left\{\mathrm{s} \geq \mathrm{t} \mid \mathrm{V}_{\mathrm{s}} \leq \mathrm{b}\right\}
$$

According to standard Brownian motion $\left(W=\{W(t)\}_{t \geq 0}\right)$; W $(0)=0$.we defines level-k first passage times: 


$$
\begin{gathered}
\tau_{K}(0)=0 ; \\
\tau_{K}(n+1)=\inf \left\{t>\tau_{K}(n):\left|W(t)-W\left(\tau_{K}(n)\right)\right| \geq b\right\}
\end{gathered}
$$

The default probability from time $t$ to time T given by

$$
\mathrm{P}[\tau \leq \mathrm{T} \mid \tau>\mathrm{t}]=\Phi\left(\mathrm{c}_{1}\right)+\exp \left\{2\left(\mathrm{r}-\frac{\sigma_{\mathrm{V}}^{2}}{2}\right) \ln \left(\frac{\mathrm{K}}{\mathrm{V}_{\mathrm{t}}}\right) \frac{1}{\sigma_{\mathrm{V}}^{2}}\right\} \Phi\left(\mathrm{c}_{2}\right)
$$

Where

$$
c_{1}=\frac{\ln \left(\frac{\mathrm{K}}{\mathrm{e}^{\mathrm{r}(\mathrm{T}-\mathrm{r})} \mathrm{V}_{\mathrm{t}}}\right)+\frac{\sigma_{\mathrm{V}}^{2}}{2}(\mathrm{~T}-\mathrm{t})}{\sigma_{\mathrm{V}} \sqrt{\mathrm{T}-\mathrm{t}}} \text {, and } \mathrm{c}_{2}=\mathrm{c}_{1}-\sigma_{\mathrm{V}} \sqrt{\mathrm{T}-\mathrm{t}}
$$

The default threshold is always positive, and it would be deterministic and exogenously fix when the firm issued their bond. Black and Cox (1976) consider a time dependent default barrier given by $e^{-\gamma(T-t)} K$, and also the default threshold is to consider $\gamma=r$ (Kim, Ramaswamy and Sundaresan (1993), and Longstaff and Schwartz (1995) consider the default threshold is constant) the default barrier given by

$$
\mathrm{D}=\mathrm{be}^{-\gamma(\mathrm{T}-\mathrm{t})}
$$

Where $\gamma$ the growth rate of the firm's liabilities and $\mathrm{b}$ is responsible for capturing the liability structure of the firm particularly, finding default barrier is the crucial challenge for any firm. Similarly as already expression for the FPM, the default takes place any time before the maturity date. The reverse, in the Merton's models (1974) the default occurs only end of maturity date, which is not reality in the fact of market. Meanwhile, we assume that the asset price of firm follows the Brownian motion in the derivatives market. Newly, Yildiray Yildirim (2006) proposed a new extension of the structural model and used the excursion theory. He defined default as a first time the process spends constant unit of time below the barrier for that time (short-time) the firm can still survive and consider the distress clock is not set zero.

\section{New Structural Approach}

Yildiray Yildirim (2006) model considers continual treading economy, free and risky coupon bonds with the interval $[0, \mathrm{~T}]$. There is a filtered probability space $\left(\Omega, \mathrm{F},\left(\mathrm{F}_{t}\right)_{0 \leqslant t \leqslant T} Q\right)$ which, the probability $Q$ is an equivalent martingale probability measure and the price of securities follow a martingale. The firm's asset follows elementary stochastic differential equation;

$$
\mathrm{dV}_{\mathrm{t}}=\sigma \mathrm{dW}_{\mathrm{t}}, \quad \mathrm{V}_{0}=\mathrm{x}
$$

Where $x>0, \sigma>0$, and $\mathrm{W}$ is a standard Brownian motion.

This model refers to time of default which is divided three ways: first way, default materialize the first time of the firm value (asset) crosses the barrierb, $\tau=\inf \left\{t>0: V_{t}=b\right\}$ Second way, default will happen when the firm value process spends an exogenously given amount of time $(\bar{b})$ below the barrier $(b)$ for the first time $\tau=\inf \{t>$ $\left.0: \int_{0}^{t} 1_{\left\{v_{s}<b\right\}} \geq \bar{b}\right\}$. Third way, Default occurs the first time the firm value process spends an amount of time after hitting the barrier.

It is so similar to excursion, then if $g_{t}^{b}=\sup \left\{\mathrm{s} \leq \mathrm{t}: V_{s}=b\right\}$ is the last time that the firm value crosses barrier before time $t$, then default happening the first time process spends $b$ unit of time below the barrier, $\tau=\inf \{t>$ $\left.0:\left(t-g_{t}^{b}\right) \geq \bar{b}\right\}$.

For the first way, the firm default is imminent or the default will be happening but for the second and third ways, if total time under the barrier widens default will occur. However, under this assumptions default depends on time spent below the barrier and respect of this issue the firm still survive whereas the firm value stays under the barrier level. Now, we want to compute the total loss firm value in the threshold level at time $t$, it could be cumulative area of the firm asset below the threshold level $b$,

$$
A_{t}=\int_{0}^{t} V_{s} 1_{\left\{V_{s}<b\right\}} d s
$$


A firm still exists before actual default, however, facing with this loss. Default time with respect of $A_{t}$, is given by

$$
\tau=\inf \left\{t>0: A_{t}>\bar{b}\right\}
$$

This formula shows, at the first time the firm value stay under the threshold level, $b$, and the total loss firm value exceeds exogenous level $\bar{b}$. The firm value can stay below the barrier point for some time. According to Yildiray Yildirim, the firm's value hits a barrier and stays under the barrier for an extended of time which is a difference between the excursions set up.

\section{Ruin Probability}

In this paper, we apply the concept of ruin probability for explain idea. First, we demonstrate a classical surplus process in continuous time.

The risk process of an insurance company in the classical way (e.g., GERBER [21] ASMUSSEN [20]):

$$
V_{t}=x+c t-\sum_{k=0}^{N_{t}} X_{i}
$$

The surplus process $\left(V_{t}\right)$ in continuous time $\left\{V_{t}\right\}_{t>o}$.it is given by a Poisson process with intensity $\lambda$ and by a positive random variable $X, i=1,2, \ldots$ are clime size which are independent and identically distributed non-negative random variable that are also independent of $N_{t}$. Meanwhile $x \geq 0$ is the initial reserve, $c$ is a constant rate of premium payment, $N_{t}$. number of claim up to time $t$. According to Dickson\& Waters the passion parameter is 1and that the mean individual claim amount is also 1 . We follow discrete time stochastic process $\{V(n)\}_{n=0}^{\infty}$ donates the surplus at time $n$ given an initial surplus of $(0)=x$, the always to be non-negative integer. The time until ruin for this process is defined as follows

$$
\begin{gathered}
T=\min \{n: V(n) \leq 0, n=1,2, \ldots\} \\
=\infty \text { if } V(n)>0 \text { for all } n>0
\end{gathered}
$$

DICKSON AND WATRES (1991) considered that if initial surplus is 0 whether ruin does not appear at time 0 but will occur at time 1 unless the aggregate claims in the first time are 0 . We looked for the probability and severity of ruin for this process, i.e. the probability that ruin occur and that the surplus at the time of ruin does not fall below $\bar{b}$ or $-y$. we define the probabilities of ruin in finite and infinite time for this process are donated $\psi(x, t)$ and $\psi(x)$ respectively and are defined as follows

$$
\begin{gathered}
\psi(x, t)=P[T \leq t] \\
\psi(x)=P[T<\infty]
\end{gathered}
$$

The probability and severity of ruin in infinite and finite time are donated $G(x, y)$ and $G(x, y, t)$, respectively. Where $y$ is a positive integer, we are defined as follow

$$
\begin{aligned}
& G(x, y)=P[T<\infty \text { and }-V(T)<\overline{\mathbf{b}}] \\
& G(x, y, t)=P[T \leq t \quad \text { and } \quad-V(T)<\overline{\mathbf{b}}]
\end{aligned}
$$

We need to calculate the probability and severity of ruin in finite and infinite time, because we believe that if the severity of ruin does not high, default has not occurred. If the value process fluctuated close to the threshold level for some time, according to Yildiray Yildirim (2006), the company capable recovers themselves in the future, in fact, it will be remain.

We looked for time of ruin which represents time of the surplus process falls below the threshold level. Since we assume that $c<\lambda \mu$ the surplus process will go to infinity with probability one. The surplus process can fluctuate under the barrier, yet be very Close to it. This does not necessarily qualify a firm to be in default. It would be interesting to find severity of ruin which is closed to (not very strong) the threshold level, the ruin has not occurred for some time. We follows Gerber: if ruin occurs, sometimes its severity is not very high and the company can have enough funds available to support some negative surplus for some time, in the hope that the portfolio will recover in the future. This allows the company to keep this business alive.

The initial capital $\mathrm{x}$ is positive. When the process reaches the threshold level that is less or equal to $b=-c / \delta$, the income would become negative. 
NOTATION: for $k=1,2, \ldots$ we donate by $f_{k}$ and $\mathrm{F}(\mathrm{k})$ the probabilities that the aggregate claims in a single time period are equal to $k$ and are less than or equal to $k$, respectvily.

We've deliberately ignored the probability and severity of ruin in finite time, just focus on the probability and severity of ruin in infinite time.

5.1 The Probability and Severity of Ruin in Infinite Time

Aggregate claims in the first unit it follows DICKSON \&WATERS (1992)

$$
\begin{aligned}
G(x, \bar{b}) & =\sum_{J=0}^{x} f_{j} G(x+1-j, \bar{b})+\sum_{J=x+1}^{x+\bar{b}} f_{j} \text { for } x=1,2,3 \ldots \\
& =\sum_{J=0}^{x} f_{j} G(x+1-j, \bar{b})+F(x+\bar{b})-F(x)
\end{aligned}
$$

Hence

$$
G(x+1, \bar{b})=f_{0}^{-1}\left(\sum_{J=0}^{x} f_{j} G(x+1-j, \bar{b})+F(x)-F(x+\bar{b})\right) \text { for } x=1,2,3, \ldots
$$

We can calculate values of $G(x, \bar{b})$ recursively from $(2.1)$.we can calculate $G(0, \bar{b})$, since

$$
G(0, \bar{b})=f_{0} G(1, \bar{b})+F(\bar{b})-F(0)
$$

And hence

$$
G(1, \bar{b})=f_{0}^{-1}(G(0, \bar{b})+F(\bar{b})-F(0))
$$

We can find $G(0, \bar{b})$ with similar method of DUFRESNE (1988), for fixed value of $\bar{b}$, define

$$
\begin{gathered}
d(0)=G(0, \bar{b}) \text { and } \\
d(x)=G(x, \bar{b})-G(x-1, \bar{b}) \quad \text { for } x=1,2,3, \ldots .
\end{gathered}
$$

Then

$$
\begin{gathered}
d(x)=\sum_{J=0}^{x-1} f_{i} d(x+1-j)+f_{x} G(1, \bar{b})+f_{x+\bar{b}}-f_{x} \quad \text { for } \quad x=1,2,3, \ldots . \\
=\sum_{J=0}^{x-1} f_{i} d(x+1-j)+f_{x+\bar{b}}-f_{x}+f_{x} d(0)
\end{gathered}
$$

Also, note that

$$
\begin{gathered}
G(0, \bar{b})=d(0)=f_{0} G(1, \bar{b})+F(\bar{b})-F(0) \\
=f_{0} d(1)+f_{0} d(0)+F(\bar{b})-F(0)
\end{gathered}
$$

Define $J(s)=\sum_{x=0}^{\infty} s^{x} d(x)$ and $H(s)=\sum_{x=0}^{\infty} s^{x} f_{x}$

Both of them generating function exist for $|s|<1$.

Then $J(s)=d(0)+\sum_{x=0}^{\infty} s^{x} d(x)$

$$
=\sum_{x=1}^{\infty} s^{x}\left(f_{x} d(0)+\sum_{j=0}^{x} f_{j} d(x+1+j)\right)+\sum_{x=1}^{\infty} s^{x}\left(f_{x+\bar{b}}-f_{x}\right)+f_{0} d(1)+f_{0} d(x)+F(\bar{b})-f_{0}
$$

Then (5.1) and (5.2) 


$$
\begin{gathered}
=\sum_{x=1}^{\infty} s^{x} \sum_{j=0}^{x} f_{j} d(x+1+j)+\sum_{x=0}^{\infty} s^{x} f_{x} d(0)+\sum_{x=1}^{\infty} s^{x} f_{x+\bar{b}}-\sum_{x=0}^{\infty} s^{x} f_{x}+F(\bar{b}) \\
=\sum_{x=1}^{\infty} s^{x} \sum_{j=0}^{x} f_{j} d(x+1+j)+(d(0)-1) H(s)+\sum_{x=0}^{\infty} s^{x} f_{x+\bar{b}}+F(\bar{b}-1) \\
=s^{-1} H(s)(J(s)-d(0))+(d(0)-1) H(s)+\sum_{x=0}^{\infty} s^{x} f_{x+\bar{b}}+F(\bar{b}-1)
\end{gathered}
$$

And hence

$$
J(s)=\frac{\sum_{x=0}^{\infty} s^{x} f_{x+\bar{b}^{+}+F(\bar{b}-1)-s^{-1} H(s) d(0)+(d(0)-1) H(s)}}{1-s^{-1} H(s)}
$$

Not that $(1)=\lim _{x \rightarrow \infty} G(x, \bar{b})=0$, and that $\mathrm{H}(1)=1$. We can find $d(0)$ from (5.3) by setting $s=1$ and then both numerator and denominator of (5.3) are zero.by applying L, Hospital's rule we will have

$$
\begin{gathered}
d(0)=\sum_{x=0}^{\infty} x f_{x}-\sum_{x=0}^{\infty} x f_{x+\bar{b}} \\
=\sum_{j=1}^{\bar{b}} j f_{j}+\bar{b} \sum_{j=\bar{b}+1}^{\infty} f_{j}=\sum_{j=0}^{\bar{b}-1}(1-F(j)) \\
\text { i.e. } G(0, \bar{b})=\sum_{j=0}^{\bar{b}-1}(1-F(j))
\end{gathered}
$$

We can calculate $G(0, \bar{b})$ as it explained in terms of the distribution function of aggregate claims per unit time. If $\bar{b} \rightarrow \infty$ on the right hand side of (5.4) then we find the mean of distribution, i.e. $1 /(1+\theta)$.

Integration equation of GERBER et al (1987), we find that,

$$
\ddot{G}(0, \bar{b})=\frac{\lambda}{c} \int_{0}^{\bar{b}}(1-P(x)) d x
$$

Where $\lambda$ is the passion parameter, $c$ is the premium income per unit time and $P(x)$ is distribution function of claim amounts. The right hand side of (5.5) shows the expected of retained aggregate claim amount per unit time under excess of loss reinsurance with threshold level $\bar{b}$, divided by the premium income per unit time before reinsurance. The right hand side of (5.4) shows the expected retained aggregate claim amount per unit under stop loss reinsurance with threshold level $\bar{b}$ divided by the premium income per unit time before reinsurance.

According to the both, DICKSON \&WATERS (1992) \& GERBER et al (1987), if the probability and severity of ruin occurs, its severity is not high for some time the company would have recovery. According to Yildiray Yildirim (2006), the financial distress level $A_{t}$ at time $\mathrm{t}$, default is defined as $\tau=\inf \left\{\mathrm{t}>0: \mathrm{A}_{\mathrm{t}}>\overline{\mathrm{b}}\right\}$ the company still survives in financial distress for some time. When the surplus process reaches the level and passes $\bar{b}$, the income would become non-positive, so the company would have not possibly of recovery for some time. Let $A_{t}$ be total loss in insurance company value with respect to an exogenous level at time $t$, which is the cumulative area of risk process below the level $b$.

$$
A_{t}=\int_{0}^{t} V_{s} 1_{\left\{V_{s}<b\right\}} d s
$$

The GERBER introduced the function

$$
G(x, b)=\operatorname{Pr}(T<\infty, b<V(T)<0)
$$


The probability that ruin occurs and that the deficit at the time of ruin is less than $b$. The corresponding density as a follow

$$
g(x, b)=\frac{d}{d b} G(x, b)
$$

Thus $g(x, b) d b$ is the probability that ruin occurs and that $V(T)$ will be between $b$ and $b+d b$.if the value process stay between 0 and $\bar{b},(0<V(t)<\bar{b})$. The Company can survive with this loss for some time before it default.in fact, that the severity of ruin for some while is not so high, and the risk process stays under the barrier level for a short time. This new definition of default overcomes the obstacle of default right after passing the threshold, and lets the firm survive even if it passes the distress level. If one has the distribution of this area, then one can price default able securities. (See Yildiray Yildirim 2006).

\section{Conclusion}

The previous versions structural models like Merton model, if the values process below the threshold level is less than the values process above the threshold default in the end of maturity, we known as default. The first passage model, it seems a little bit different status it means that the firm's value can be faced default any time, during of a debt. The new structural approach refers to that if the value process passed the threshold level; it didn't means that the default occurred so the firm would survive for some time. We used the probability of ruin to explain this situation. If the ruin occurred sometimes its severity was not particularly high, and the company can have enough funds available to support some negative surplus for some time. The default is triggered the first time that the cumulative area of the process, means that the price of below a threshold level.

\section{References}

Andersen, L., \& Andreasen, J. (1998). Volatility skews and extensions of the Libor market model. Working paper, General Re Financial Products.

Andersen, L., \& Brotherton-Ratcliffe, R. (2001). e. Extended Libor market models with stochastic volatility. Working paper, General Re Financial Products.

ASMUSSEN, S. (2000). Ruin Probabilities. World Scientific Press.

Black, F., \& J.C. Cox. (1976). Valuing Corporate Securities: Some Effects of Bond Indenture Provisions. Journal of Finance, 31, 351-367. http://dx.doi.org/10.1111/j.1540-6261.1976.tb01891.x

Black, F., \& Scholes, M. (1973). The pricing of Optionsans Corporat Liabilities. Journal of Political Economy, 81, 637-654. http://dx.doi.org/10.1086/260062

Briys, E., \& de Varenne, F. (1997). Valuing Risky Fixed Rate Debt: An Extention. Journal of Financial and Quantitative Analysis, 31, 239-248. http://dx.doi.org/10.2307/2331175

Cornwall, J., \& Kentwell, G. (1995). A Quasi-Analytical Approach to Occupation Time Barrier. Bankers Trust Working Paper.

David C. M Dickson, \& Howard R.Waters. (1992). The probability and severity of ruin in finite and infinite time. ASTIN BULLETIN, 22.

Dufresne, F., \& Gerber, H.U. (1988). The Probability and severity of ruin forcombinations of exponential claim amount distributions and their translations. Insurance: Mathematics and Economics, 7, 75-80. http://dx.doi.org/10.1016/0167-6687(88)90100-X

Gerber, H. (1973). Martingales in risk theory. Mitt. Ver.Schweiz Vers. Math, 73, 205-216.

Geske, R. (1977). The Valuation of Corporate Liabilities as Compound Options. Journal of Finance and Quantitatives, 6, 541-552. http://dx.doi.org/10.2307/2330330

Geske, R. (1979). The Valuation of Compound Option. Journal of Financial Econmics, 7, 63-81.

Hsu, J., Saa-Requejo, J., \& Santa-Clara, P. (2004). Bond Pricing with Default Risk. UCLA Working Paper.

K. L. C. (1976). Excursions in Brownian motion. Ark fur math, 14, 155-177. http://dx.doi.org/10.1007/BF02385832

Kim, I. J., Ramaswamy, K., \& Sundareson, S. M. (1993). Does default risk in coupons affect the valuation of corporate bonds?: A contingent claims model. Financial Management, 22, 117-131. http://dx.doi.org/10.2307/3665932 
Leland, H. (1994). Risky Debt, Bond Covenants and Optimal Capital Structure. Journal of Finance, 49, 1213-1252. http://dx.doi.org/10.1111/j.1540-6261.1994.tb02452.x

Leland, H. E. (n.d.). Predictions of Default Probabilities in Structural M odels of Debt. Journal of Investment Managements.

Leland, H. E., \& Toft, K. B. (1996). Optimal Capital Structure, Endogenous Bnkruptcy and the Term Structure of Credit Spreads. Journal of Finance, 50, 789-819.

Longstaff, F.A., \& Schwartz, E. S. (1995). A Simple Approach to Valuing Risky Fixed and Floating Rate Debt. Journal of Finance, 50, 789-819. http://dx.doi.org/10.1111/j.1540-6261.1995.tb04037.x

Merton, R. (1974). On the Pricing of Corporate Debt:the Risk Structure of Interest Rates. Journal of Finance, 29, 449-470.

Yildirm, Y. (2006, April 27). Modelling default risk: A new atructural approach.

Zhou, C. (2001). The Terms Structure of Credit Spreads with Jump. Journal of Finance, 25, 2015-2040.

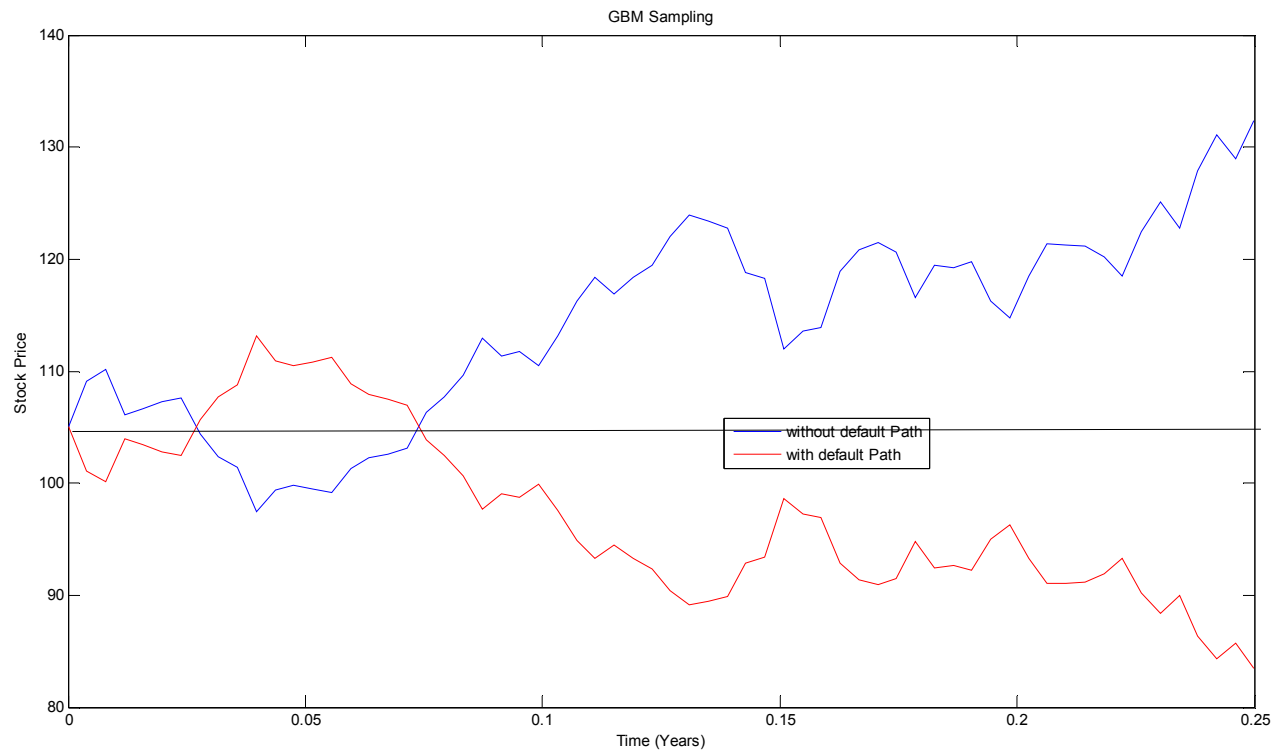

Figure 1. Brownian motion with the threshold level from $\mathrm{t}=0$ to maturity date (Using MATLAB software with two paths) 


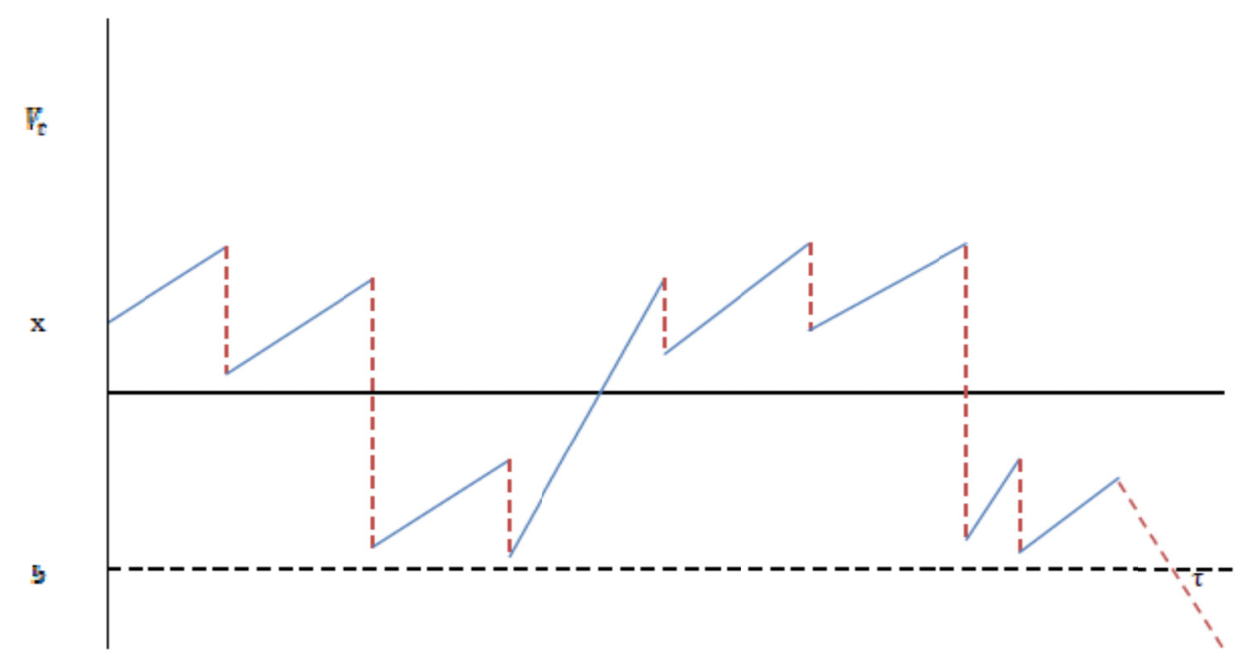

Figure 2. The surplus process and cumulative area of process below threshold level

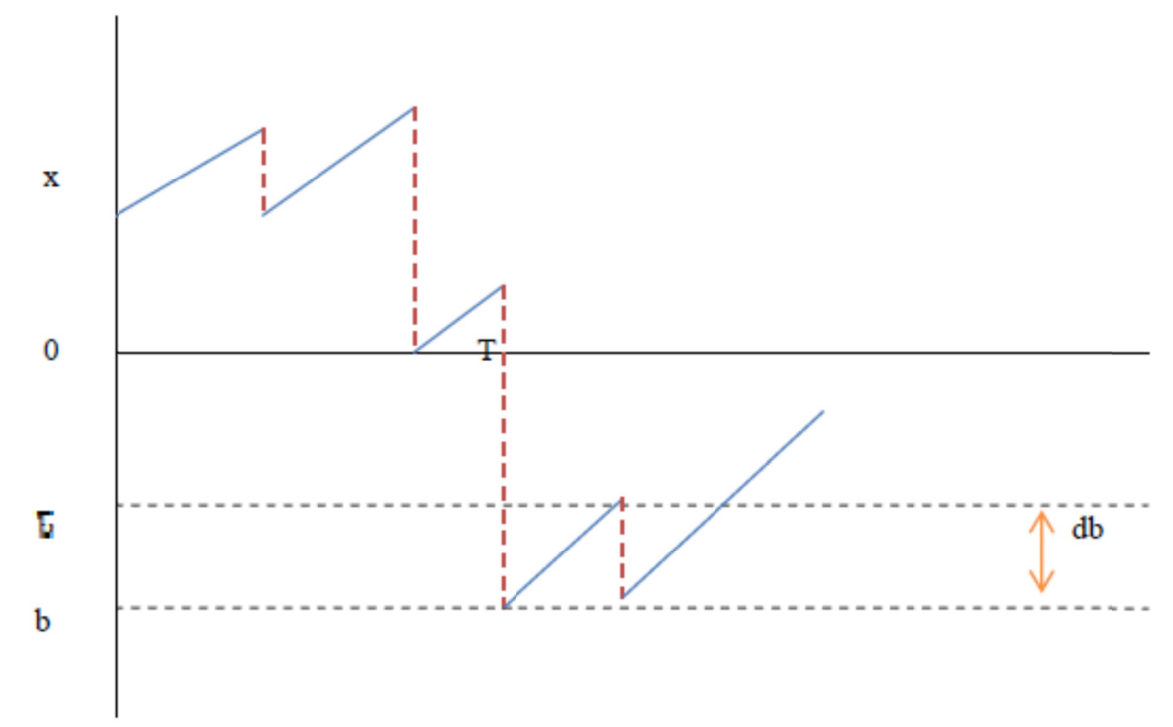

Figure 3. The interpretation $g(x, b) d b$ according to GERBER 